\title{
Contribution of IL-33 to the Pathogenesis of Colorectal Cancer
}

\author{
Guanglin Cui ${ }^{1,2 *}$, Aping Yuan ${ }^{1}$, Zhigang Pang ${ }^{1}$, Wei Zheng ${ }^{1}$, Zhenfeng $\mathrm{Li}^{1}$ and \\ Rasmus Goll ${ }^{3}$ \\ ${ }^{1}$ Research Group of Gastrointestinal Diseases, The Second Affiliated Hospital of Zhengzhou University, Zhengzhou, China, \\ ${ }^{2}$ Faculty of Health Science, Nord University, Levanger, Norway, ${ }^{3}$ Department of Gastroenterology, University Hospital of \\ North Norway, Tromsø, Norway
}

The development of colorectal cancer $(\mathrm{CRC})$ is not only determined by transformed cells per se, but also by factors existing in their immune microenvironment. Accumulating scientific evidence has revealed that interleukin (IL)-33, an IL-1 family member, plays an essential role in the regulation of immune response and is relevant in CRC pathogenesis. Data from both human and experimental studies demonstrated that IL-33 inhibits host anti-tumor immunity, remodels tumor stroma and enhances angiogenesis, thereby promoting the development of CRC. These pro-tumor effects of IL-33 are mainly mediated by IL-33 receptor ST2 (also known as IL-1RL1). Based on those findings, it is currently hypothesized that the IL-33/ST2 pathway is a potential biomarker and therapeutic target for colorectal tumorigenesis. Herein, we summarize the recent discoveries in understanding the critical role of the IL-33/ST2 pathway in contributing to

OPEN ACCESS

Edited by:

Saverio Marchi,

University of Ferrara, Italy

Reviewed by:

Diego Luis Costa,

National Institute of Allergy and Infectious Diseases (NIAID),

United States

Marcela A. Hermoso,

Universidad de Chile, Chile

*Correspondence:

Guanglin Cui

guanglin.cui@nord.no

Specialty section: This article was submitted to Molecular and Cellular Oncology, a section of the journal Frontiers in Oncology

Received: 29 June 2018 Accepted: 12 November 2018 Published: 28 November 2018

Citation:

Cui G, Yuan A, Pang Z, Zheng W, Li Z and Goll R (2018) Contribution of IL-33

to the Pathogenesis of Colorectal

Cancer. Front. Oncol. 8:561.

doi: 10.3389/fonc.2018.00561 the pathogenesis of colorectal tumorigenesis and discuss its potential implications for the future development of effective anti-tumor strategies.

Keywords: colorectum, tumorigenesis, cytokine, IL-33, ST2

\section{INTRODUCTION}

Colorectal cancer (CRC) is a leading cause of cancers mortality worldwide. The initiation and development of CRC is not only determined by the genetic and molecular characteristics of transformed cells per se, but also by factors existing in their immune microenvironment (1-3).

Host immune function is one of the most important factors contributing to the development of CRC (4-6). The interaction between host immunity and transformed cells might significantly influence the establishment of CRC $(1,2,7)$. It has been known for a number of years that there is a significant impairment of host anti-tumor immunity during the initiation of CRC because transformed cells, in order to escape host immune attack, use diverse strategies to suppress anti-tumor immunity and form a favorable growth milieu. Therefore, there is great interest in studying the contributing factors of immune microenvironment formation in premalignant and malignant lesions.

The lack of an effective immune response to tumorigenesis, in spite of the presence of dense tumor infiltrating lymphocytes in the tumor microenvironment, is believed to be due in some way to the action of immunosuppressive immune cells/cytokines (8-10). Certain cytokines can significantly affect the initiation/progression of CRC $(1,11-14)$, acting not only as the promotors for tumor cell growth but also as important contributor for the immune suppressive

Abbreviations: CRC, colorectal cancer; IL, interleukin; Treg, regulatory T cell; IR, immunoreactivity; IBD, inflammatory

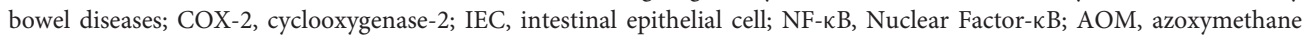
(AOM); DSS, dextran sodium sulfate. 
microenvironment formation during tumor development (4, 15-25). Therefore, the improved characterization of cytokine networks will greatly add help in understanding the cross-talk between transformed cells and their microenvironment, thereby presenting the prospect of designing novel translational/targeted approaches to tumors $(14,26-28)$. In the study of cytokine networks in the colorectal tumorigenesis, a greatly altered cytokine profile during progression of adenomas to CRCs has been demonstrated $(14,18,29-31)$, in which the level of Th1 cytokines is decreased but the expression level of Th2 cytokines is significantly increased from adenomas to CRCs (5, $6,32,33)$. Further immunohistochemical analysis demonstrated that adenoma/CRC epithelium significantly contributes to the production of cytokines (5, 20, 23, 34-38), whereas, blocking cytokine signaling may suppress the development and establishment of both premalignant and malignant lesions in animal models $(39,40)$. Numerous studies strongly suggest that cytokines are key factors in influencing the development of CRC $(2,15,35,41,42)$.

IL-33 is a novel pro-inflammatory cytokine that belongs to the IL-1 family. IL-33 plays an important role in the regulation of host immune responses (43-45) and has been associated with human inflammatory bowel diseases (IBD) $(46,47)$, as well as tumors (48-55). Moreover, studies have also revealed that high expression of IL-33 is associated with poor prognosis in diverse cancers and may be a potential prognostic predicator $(52,54-$ 58). Current data strongly suggest that IL-33 is involved in the pathogenesis of CRC $(19,59,60)$.

In view of the importance of IL-33 in contributing to the pathogenesis of CRC, herein, we review the critical role of IL33 in the pathogenesis of CRC development and evaluate its potential as biomarker for assessing tumor aggressiveness and disease prognosis. In addition, the possible role of IL-33 and its receptor, ST2, as novel biomarkers and therapeutic targets is discussed.

\section{CELLS EXPRESSING IL-33 AND ITS FUNCTIONAL RECEPTOR, ST2, IN THE TUMOR MICROENVIRONMENT}

We previously examined cell expressing IL-33 and ST2 in the human adenoma/CRC microenvironment. Results showed that IL-33 immunoreactivity (IR) is observed in diverse cells, including adenoma/CRC cells, CD3 positive lymphocytes, SMAalpha positive myofibroblasts and CD34 positive endothelial cells of tumor-associated microvessels (19). IL-33 functions as a proinflammatory cytokine by binding to the heterodimeric ST2 receptor complex (46). Interestingly, ST2 in the adenoma/CRC microenvironment is expressed in a very similar cellular pattern as IL-33. ST2-IR has been clearly identified in adenoma/CRC cells, lymphocytes, myofibroblasts and endothelial cells of microvessels (19). Those observations indicate that IL-33 and ST2 within the adenoma/CRC microenvironment originate from a mixed cellular source and provide important information for understanding the interaction between IL-33 and its receptor, ST2, in promoting colorectal tumorigenesis.

\section{PROMOTING EFFECTS OF IL-33 ON THE DEVELOPMENT OF COLORECTAL TUMORIGENESIS}

Chronic inflammation is a major risk factor for the development of $\operatorname{CRC}(1,15,61)$, and IL-33 is a potent pro-inflammatory cytokine that plays a critical role in the initiation of colorectal mucosal inflammation $(62,63)$. Thus, studies regarding the role of IL-33 in the CRC development in animal models has attracted much attention and evidence is accumulating.

The one animal study of interest with respect to IL-33 and the formation of premalignant adenoma was performed in mice. Maywald et al. examined the promoting effect of IL-33 in the formation of polyps (adenomas) in traditional ApcMin/+ mice with an IL-33 deficient background (59). They found that IL-33 deficiency significantly reduced the formation of intestinal polyposis (adenoma) and mast cell accumulation in adenomatous polyps, suppressing the expression of mast cellderived proteases and cytokines known to promote polyposis in ApcMin/+ mice (59). Thus, their findings suggest that IL33 promotes the formation of intestinal adenomas through coordinated activation of stromal cells and formation of a protumorigenic microenvironment (59).

We have examined the expression profile of IL-33 in human adenomas and found that expression levels of IL33 mRNA are markedly increased in adenoma tissues (19). This finding might imply that IL-33 is an early immune response element reacting to the initiation of premalignant adenomas. Immunohistochemical results revealed that IL-33-IR was highly expressed in adenoma cells, lymphocytes, stromal cells (myofibroblasts) and microvessels, indicating an autocrine/paracrine loop in those cells. Particularly, the density of IL-33-positive microvessels was significantly increased in adenoma stroma compared to normal controls (19). These findings suggest that elevated IL-33 may participate in the regulation of tumor associated angiogenesis during the progression of adenomas. Indeed, we have found that the expression level of IL-33 mRNA is associated with dysplastic degree in adenomas (19). Those findings suggest the hypothesis that IL-33 participates in the pathogenesis of premalignant adenomas.

Regarding the role of IL-33 in the pathogenesis of CRC, numerous studies have been conducted in animals and humans.

Using mice treated with the chemical carcinogen azoxymethane (AOM) and the inflammatory inducer dextran sodium sulfate (DSS), Islam et al. revealed that epidermal growth factor is a key growth factor in intestinal epithelial cell (IEC)-derived IL-33 promotion of tumorigenesis (64). Most current human studies are performed in established human CRCs $(19,59,63)$. Results have showed increased expression levels of IL-33 at both the protein and transcriptional levels in human CRC tissues (19). Interestingly, increased expression levels of IL-33 and ST2 were more frequently observed in low-grade adenocarcinomas than high-grade adenocarcinomas (63). Our immunohistochemical analysis has shown that many types of cells within the CRC microenvironment can express 
both IL-33 and ST2. As illustrated in adenomas, we also found that both IL-33- and ST2-IRs are expressed in CRC cells, CD3 positive lymphocytes, SMA-alpha positive myofibroblasts, and CD34 positive microvessels within the CRC microenvironment. Our findings suggest that elevated expression of IL-33 and ST2 in CRC tissues may come from a mixed cellular source, and IL-33 could have far-reaching biological effects on diverse cells within the CRC microenvironment.

\section{CONTRIBUTION OF DIFFERENT FORMS OF THE IL-33 RECEPTOR TO THE DEVELOPMENT OF COLORECTAL TUMORIGENESIS}

The IL-33 receptor exists in the following two forms as splice variants: (1) a soluble form (sST2), which acts as a decoy receptor, sequesters free IL-33, and does not signal; and (2) a membrane-bound form (ST2), which activates MyD88/NF$\kappa \mathrm{B}$ signaling to enhance mast cell, Th2, Treg cells, and innate lymphoid cell type 2 functions (65). Therefore, the functions for these two receptor forms are completely different. It has been reported that the expression level of ST2 is significantly increased in both animal and human CRC tissues $(19,63)$. Moreover, the administration of ST2 antibody in ApcMin/+ mice results in significantly reduced both tumor number and size compared to control mice, accompanied by a significant inhibition of proliferation and angiogenesis, with increased apoptosis in adenomatous polyps (59). Mertz KD and colleagues examined the role of ST2 in the development of colorectal tumorigenesis in an ST2-/- deficient mouse model (63). They found that deficiency of ST2 in mice results in a protective effect against AOM/DSS-triggered CRC, with significantly reduced tumor load compared with control mice. In addition, their results also suggested that the promoting effect of the IL-33/ST2 axis on colonic tumorigenesis occurs via the production of IL-6 (63). Their results strongly suggest that ST2 is a key mediator for IL-33 induced colorectal tumorigenesis (63). We examined the expression profile of ST2 in both human adenomas and CRCs (19). Results demonstrated that increased expression of ST2 is found in adenoma tissues and persists to in CRC tissues. ST2IR is highly expressed in adenoma/CRC cells, stromal cells and microvessels within the tumor microenvironment (19). Since ST2 plays an essential role in the regulation of host immune response, Treg accumulation, and angiogenesis, our findings indicates that increased expression of ST2 participates in the development of CRC.

The function of sST2 is different from that of ST2, and the role of sST2 during the progression of CRC has also been examined. One study revealed that the expression level of sST2 in cancer tissues is lower than that in adjacent nontumor tissues. In addition, patients with advanced TNM stage have lower expression of sST2 (66). They only found differences in ST2, sST2 was only measured in plasma with no difference between patients $v s$. healthy subjects. Which suggests that the ST2 variant might have an anti-tumorigenic role in the CRC. In contrast to O’Donnell's results (66), Miho Akimoto et al. reported that sST2 is a negative regulator for tumor growth and metastasis (67). They found that expression levels of sST2 are inversely associated with the malignant growth of CRC, and SST2 is down regulated in highly metastatic cells compared with low metastatic human and mouse CRC cells. Knockdown of sST2 in low metastatic SW480 cells (CRC cell line derived from the primary tumor site) with sST2 short hairpin RNA (shRNA) enhances tumor cell growth and tumor formation, whereas its overexpression in highly metastatic SW620 cells (CRC cell line derived from the metastatic site from the same patient) inhibits these processes. The SW480shsST2 cells efficiently formed tumors (7 out of 7 mice), whereas the SW480-shCont (the control shRNA-expressing) cells seldom formed tumors ( 1 out of 7 mice). It has been previously shown that IL-33 exhibited a proangiogenic effect in human umbilical vein endothelial cells (HUVECs) via Akt signaling (68). The authors have therefore examined the ratio of phospho-Akt/total Akt in HUVECs treated with rIL-33 alone or in combination with rsST2. They found that rIL-33 promoted Akt phosphorylation, and phosphorylation was decreased by co-treatment with rsST2. Similarly, a thymidine incorporation assay, migration assay and tube formation assay using a two-dimensional Matrigel revealed the inhibitory effect of rsST2 on rIL-33-induced responses of HUVECs (67). Thus, they concluded that sST2 is involved in the regulation of IL-33 on angiogenesis. These two reports have provided different results. Therefore, further studies regarding the exact role of sST2 in CRC progression still needed.

Collectively, these results obtained from both animal and human studies suggest that colorectal tumorigenesis elicits a strong IL-33 response, and this response may contribute to the development of both premalignant and malignant lesions.

\section{MECHANISMS OF IL-33 PROMOTING THE DEVELOPMENT OF CRC}

The precise mechanisms whereby IL-33 promotes the development of CRC remain unclear, though several potential mechanisms have been hypothesized and evaluated.

A direct effect on colorectal epithelial cells: A direct promoting effect of IL-33 on cell transformation has been observed in other types of human cancers (49). However, Mertz KD et al. revealed that the promoting effect of IL-33 on the development of CRC in mice does not directly affect the proliferation of tumor cells in animal CRC models (63).

Induction of other pro-tumorigenic factors: Cyclooxygenase2 (COX-2), IL-6 and IL-17A are potent pro-tumorigenic factors that encourage the development of CRCs $(22,24,30,69$, $70)$. It was recently shown that the stimulating effect of IL33 on cell proliferation in vitro with primary CRC cells, as well as CRC cell lines, depends on activation of the COX2/PGE2 pathway (71). The COX-2 selective inhibitor and PGE2 neutralizing antibody significantly attenuated such proliferationpromoting effects induced by IL-33 administration (71). IL$17 \mathrm{~A}$ is another pro-inflammatory cytokine with a strong protumorigenic capacity. Studies have also shown that serum concentrations of IL-33 are associated with upregulated levels of IL-17A in patients with autoimmune hepatitis, whereas specific 
inhibition of IL-33 by treatment with a specific neutralizing antibody significantly reversed the level of IL-17A in a murine model with autoimmune hepatitis (72). Moreover, a recent study demonstrated that IEC-derived IL-33 regulates the accumulation of Th17 cells (a main cellular source of IL-17A) in the small intestine (73). In addition, IL-6 is also reported to be an important mediator for IL-33 in promoting the formation of CRC in ST2 deficient mice (63). Since IL-6 is an upstream stimulator of IL-17A production from Th17 cells, the IL-33-IL6-IL-17A pathway may play a critical role in the development of CRC.

Remodeling tumor stroma and pro-angiogenesis: IL-33 markedly stimulates myofibroblasts to produce several types of extracellular matrix components including MMP2, MMP9, and growth factors associated with CRC tumor growth, progression and metastasis $(63,67,74)$. Such stromal remodeling effects of IL-33 have been shown to promote tumor cell growth and liver metastasis in IL-33-deficient mice with a metastatic murine CRC cell line (60).

IL-33 is a cytokine with strong pro-angiogenic capabilities $(68,75,76)$, and one of the potential mechanisms for IL-33 in promoting CRC progression maybe due to the enhanced angiogenesis (60). We know that the IL-33 receptor, ST2, is highly expressed in the endothelial cells of microvessels that mediate potential proangiogenic effects of IL-33 $(19,68)$. YeonSook Choi et al. demonstrated that IL-33 increases proliferation and differentiation of human endothelial cells and increases angiogenesis in vivo (68). We previously demonstrated increased densities of IL-33 positive and ST2 positive microvessels in adenoma/CRC stroma, suggesting that microvessels are not only the cellular sources of IL-33 and ST2 may also be autocrine or paracrine targets for IL-33/ST2 in regulating angiogenesis in the adenoma/CRC microenvironment (19). IL33 can stimulate the production of pro-angiogenic factors (77, 78), vascular endothelial growth factor (VEGF), and IL8 , are well-known pro-angiogenic factors in human cancers including CRC $(18,79)$. There is evidence to show that IL33 strongly stimulates production of VEGF and IL-8 in vitro $(77,78)$. We and others have reported significant increase of IL-8 and VEGF expression in human adenoma and CRC specimens $(18,19,80)$, which are similar to the expression profile of IL-33 in adenoma and CRC specimens. Therefore, these findings may suggest a possible regulatory effect of IL33 on the induction of pro-angiogenic factors during colorectal tumorigenesis.

Induced suppressive immune cell accumulation: Numerous studies have demonstrated that IL-33 can greatly influence various immune cells during differentiation, immune responses and homeostasis $(45,65)$. Thus, one of the possible mechanisms for IL-33 in promoting human cancer progression is through increased accumulation of immunosuppressive cells within the tumor microenvironment and by diminishing innate antitumor immunity. The IL-33/ST2 axis has a potential role in the expansion and function of diverse immune cells (65). Accumulation of Tregs in the tumor microenvironment is a common phenomenon in both colorectal premalignant and malignant lesions $(8,81,82)$. IL-33 can induce the enhanced recruitment of suppressive immune cells such as CD11b+ GR1+ and CD11b+ F4/80+ myeloid cells and Tregs into the tumor site, where these cells have a strong impact on immune microenvironment remodeling $(60,83)$. Exogenously administered recombinant mouse IL33 significantly potentiates tumor burden and induces ST2 positive Tregs infiltrated into tumor masses. In contrast, neutralizing IL-33 or ST2 by administration of antibodies remarkably inhibits tumor size and decreases the density of ST2 positive Tregs inside tumor masses in tumor-bearing mice (84). Thus, the accumulation of suppressive immune cells in the tumor microenvironment might play a role in the regulation of host immune response during CRC development.

Therefore, although the exact mechanism of IL-33's promotion of CRC development is still unknown, its protumor function in the colorectal mucosa is likely due to a combination of several mechanisms (see Figure 1).

\section{COULD IL-33 BE A POTENTIAL BIOMARKER AND NEW THERAPEUTIC TARGET FOR COLORECTAL TUMORIGENESIS?}

It was previously demonstrated that IL-33 and ST2 at mRNA and protein levels are increased in both premalignant and malignant tissues $(19,63,85)$. In our study, we investigated the clinical significance of IL-33 and ST2 as novel clinicopathological biomarkers in patients with premalignant adenomas and CRCs. General analysis revealed that no clinicopathological parameters were associated with tissue levels of either IL-33 or ST2 mRNAs in patients with adenomas. However, tissue expression levels of ST2 in CRC patients were associated with TNM stage, and patients with advanced TNM stage had a higher ST2 mRNA level than those with early stage disease (19). It has been established that the expression level of IL-33 is associated with poor prognosis and predicts unresponsiveness to chemotherapy in certain cancers, including CRC $(55,56,58,86)$. We therefore analyzed the relationship between expression levels of IL-33/ST2 and overall survival in patients with CRCs. However, our Kaplan-Meier analysis did not confirm a correlation between concentrations of either IL-33 or ST2 at the mRNA level with overall survival times in CRC patients (19). These results indicate that whether high expression levels of IL-33 and ST2 mRNA could serve as a marker of disease aggressiveness in patients with CRC is still questionable. IL-33 and ST2 are expressed in a variety of cells, including epithelial cells, stromal cells, infiltrating lymphocytes and microvessels (19), and IL-33 and ST2 at the mRNA level of whole CRC specimens quantified by real-time PCR may not differentiate the expression level of IL-33 and ST2 in various compartments of the tumor microenvironment. Therefore, a future priority is to investigate the relationship between expression levels of IL-33 and ST2 in various compartments and clinicopathological variables.

Many efforts have been directed toward the inhibition of cytokine networks as new therapeutic targets for CRC 


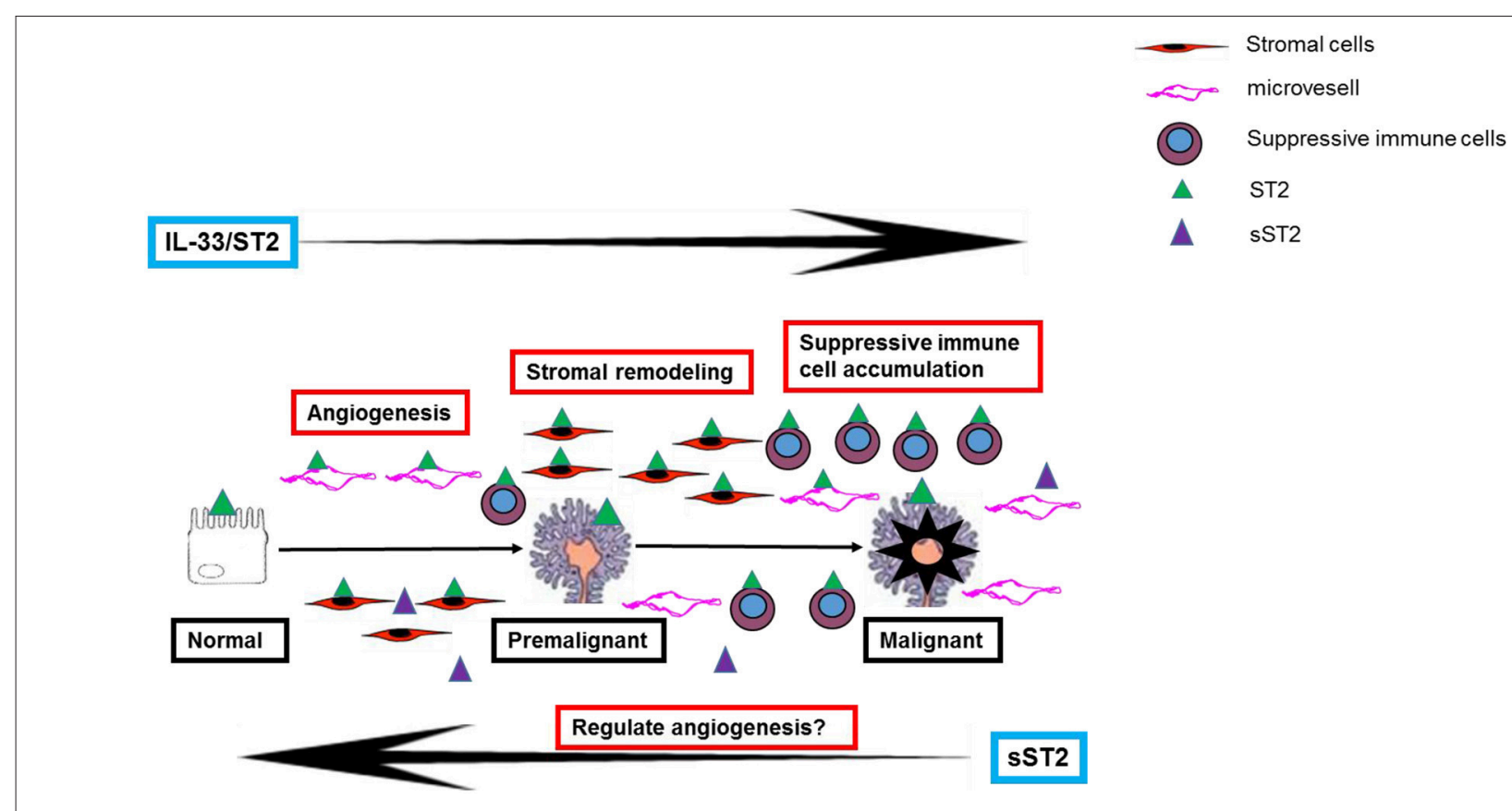

FIGURE 1 | A schematic representation of the potential mechanisms of IL-33 in contributing to the development of colorectal premalignant and malignant lesions.

development (87). The IL-33/ST2 axis as a new therapeutic target during the CRC development has also been evaluated. One study to show that the blockade of ST2 signaling through the administration of a ST2 antibody suppresses the development of CRC in ApcMin/+ mice (59). Similarly, ST2 deficiency reduces tumor number, size, and dysplastic grade in the intestine of AOM/DSS-dosed mice $(63,88)$.

Because angiogenesis is a critical step for the growth, expansion and metastasis of CRCs, targeting angiogenesis has become one of the therapeutics for treating CRCs (87). As we stated previously, IL-33 is a potent pro-angiogenic factor that markedly enhances angiogenesis during tumor development. We and others have previously demonstrated that both IL-33 and ST2 are highly expressed in tumorassociated microvessels, implying autocrine stimulation of angiogenesis during the progression of CRC (19). Cytokine signaling can be easily targeted pharmacologically (89), and several studies have examined the inhibitory efficacy of IL33 or ST2 signals in murine CRC models. However, cytokine networks in tumors are very complex; one cytokine may have a wide range of biological effects, while different cytokines may possess the same function (38). Although most studies demonstrate that IL-33 promotes the development of CRC, the antitumor effect of IL-33 has also been reported at least in some tumor models (90-92). Therefore, one should take into consideration that IL-33 might have a more complex effect on the development of CRC when designing therapeutic interventions targeting IL-33 or ST2 signaling. Fundamental questions regarding the mechanisms of IL-33 or ST2 signal blockade in preventing the development of CRC remain to be further investigated.

\section{CONCLUSIONS AND FUTURE PERSPECTIVES}

Cumulative evidence from both animal and human studies strongly supports that IL-33 plays an important role in dictating the development and growth of colorectal cancer through regulation of host anti-tumor immunity, angiogenesis and stromal remodeling that are found in the tumor microenvironment. Based on the findings of the studies outlined in this review, IL-33 as a potential contributor and therapeutic target for the development of colorectal tumorigenesis has been considered, which may benefit the design of new medicines for the treatment of CRC. However, many fundamental questions remain.

\section{AUTHOR CONTRIBUTIONS}

GC and AY offered direction on the project and drafted the manuscript. $\mathrm{ZP}, \mathrm{WZ}, \mathrm{ZL}$, and RG reviewed the manuscript and made significant revisions to the manuscript. All authors read and approved the final manuscript.

\section{FUNDING}

This project was supported by the Medical Research Program, Northern Norway Regional Health Authority (Program No. SFP-44-04), the Innovation Scientists and Technicians Troop Construction Projects of Henan Province (CXTD20150009), the Nature and Science Foundation of Henan Province (Program No. 182300410326), and the Scientific and Technological Research Project of Henan Province, China (Program No. 182102310383). 


\section{REFERENCES}

1. Shi Y, Li Z, Zheng W, Liu X, Sun C, Laugsand JB, et al. Changes of immunocytic phenotypes and functions from human colorectal adenomatous stage to cancerous stage: update. Immunobiology (2015) 220:1186-96. doi: 10.1016/j.imbio.2015.06.003

2. McLean MH, Murray GI, Stewart KN, Norrie G, Mayer C, Hold GL, et al. The inflammatory microenvironment in colorectal neoplasia. PLoS ONE (2011) 6:e15366. doi: 10.1371/journal.pone.0015366

3. Schreiber RD, Old LJ, Smyth MJ. Cancer immunoediting: integrating immunity's roles in cancer suppression and promotion. Science (2011) 331:1565-70. doi: 10.1126/science. 1203486

4. Cui G, Yuan A, Goll R, Olsen T, Husebekk A, Vonen B, et al. Distinct changes of dendritic cell number and IL-12 mRNA level in adjacent mucosa throughout the colorectal adenoma-carcinoma sequence. Cancer Immunol Immunother. (2007) 56:1993-2001. doi: 10.1007/s00262-007-0345-9

5. Cui G, Goll R, Olsen T, Steigen SE, Husebekk A, Vonen B, et al. Reduced expression of microenvironmental Th1 cytokines accompanies adenomascarcinomas sequence of colorectum. Cancer Immunol Immunother. (2007) 56:985-95. doi: 10.1007/s00262-006-0259-y

6. Cui G, Florholmen J. Polarization of cytokine profile from Th1 into Th2 along colorectal adenoma-carcinoma sequence: implications for the biotherapeutic target? Inflamm Allergy Drug Targets (2008) 7:94-7. doi: $10.2174 / 187152808785107589$

7. Croci DO, Zacarias Fluck MF, Rico MJ, Matar P, Rabinovich GA, Scharovsky OG. Dynamic cross-talk between tumor and immune cells in orchestrating the immunosuppressive network at the tumor microenvironment. Cancer Immunol Immunother. (2007) 56:1687-700. doi: 10.1007/s00262-007-0343-y

8. Hua W, Yuan A, Zheng W, Li C, Cui J, Pang Z, et al. Accumulation of FoxP3 $^{+} \mathrm{T}$ regulatory cells in the tumor microenvironment of human colorectal adenomas. Pathol Res Pract. (2016) 212:106-12. doi: 10.1016/j.prp.2015.12.002

9. Maihofner C, Charalambous MP, Bhambra U, Lightfoot T, Geisslinger G, Gooderham NJ, et al. Expression of cyclooxygenase-2 parallels expression of interleukin-1beta, interleukin-6 and NF-kappaB in human colorectal cancer. Carcinogenesis (2003) 24:665-71. doi: 10.1093/carcin/bgg006

10. Lin WW, Karin M. A cytokine-mediated link between innate immunity, inflammation, and cancer. J Clin Invest. (2007) 117:1175-83. doi: 10.1172/JCI31537

11. Lasry A, Zinger A, Ben-Neriah Y. Inflammatory networks underlying colorectal cancer. Nat Immunol. (2016) 17:230-40. doi: 10.1038/ni.3384

12. Hopkins MH, Flanders WD, Bostick RM. Associations of circulating inflammatory biomarkers with risk factors for colorectal cancer in colorectal adenoma patients. Biomarker Insights (2012) 7:143-50. doi: $10.4137 /$ BMI.S10092

13. Fantini MC, Pallone F. Cytokines: from gut inflammation to colorectal cancer. Curr Drug Targets (2008) 9:375-80. doi: 10.2174/138945008784221206

14. Mager LF, Wasmer MH, Rau TT, Krebs P. Cytokine-induced modulation of colorectal cancer. Front Oncol. (2016) 6:96. doi: 10.3389/fonc.2016.00096

15. Moossavi S, Bishehsari F. Inflammation in sporadic colorectal cancer. Arch Iran Med. (2012) 15:166-70.

16. Wu P, Wu D, Ni C, Ye J, Chen W, Hu G, et al. gammadeltaT17 cells promote the accumulation and expansion of myeloid-derived suppressor cells in human colorectal cancer. Immunity (2014) 40:785-800. doi: 10.1016/j.immuni.2014.03.013

17. Wang K, Karin M. Tumor-elicited inflammation and colorectal cancer. $A d v$ Cancer Res, (2015) 128:173-96. doi: 10.1016/bs.acr.2015.04.014

18. Cui G, Yuan A, Goll R, Vonen B, Florholmen J. Dynamic changes of interleukin-8 network along the colorectal adenoma-carcinoma sequence. Cancer Immunol Immunother. (2009) 58:1897-905. doi: 10.1007/s00262-009-0702-y

19. Cui G, Qi H, Gundersen MD, Yang H, Christiansen I, Sorbye SW, et al. Dynamics of the IL-33/ST2 network in the progression of human colorectal adenoma to sporadic colorectal cancer. Cancer Immunol Immunother. (2015) 64:181-90. doi: 10.1007/s00262-014-1624-x

20. Cui G, Yang H, Zhao J, Yuan A, Florholmen J. Elevated proinflammatory cytokine IL-17A in the adjacent tissues along the adenoma-carcinoma sequence. Pathol Oncol Res. (2015) 21:139-46. doi: 10.1007/s12253-014-9799-1

21. Cui J, Xu G, Liu J, Pang Z, Florholmen J, Cui G. The expression of nonmast histamine in tumor associated microvessels in human colorectal cancers. Pathol Oncol Res. (2013) 19:311-6. doi: 10.1007/s12253-012-9584-y

22. Cui G, Yuan A, Sun Z, Zheng W, Pang Z. IL-1beta/IL-6 network in the tumor microenvironment of human colorectal cancer. Pathol Res Pract. (2018) 214:986-92. doi: 10.1016/j.prp.2018.05.011

23. Cui G, Yuan A, Goll R, Florholmen J. IL-17A in the tumor microenvironment of the human colorectal adenoma-carcinoma sequence. Scand J Gastroenterol. (2012) 47:1304-12. doi: 10.3109/00365521.2012.725089

24. Shi Y, Lin H, Cui J, Qi H, Florholmen J, Liu Z, et al. The role of interleukin-17A in colorectal tumorigenesis. Cancer Biother Radiopharm. (2013) 28:429-32. doi: $10.1089 /$ cbr.2012.1396

25. Donadon M, Lleo A, Di Tommaso L, Soldani C, Franceschini B, Roncalli M, et al. The shifting paradigm of prognostic factors of colorectal liver metastases: from tumor-centered to host immune-centered factors. Front Oncol. (2018) 8:181. doi: $10.3389 /$ fonc. 2018.00181

26. Atreya R, Neurath MF. Involvement of IL-6 in the pathogenesis of inflammatory bowel disease and colon cancer. Clin Rev Allergy Immunol. (2005) 28:187-96. doi: 10.1385/CRIAI:28:3:187

27. Schwartz SA, Hernandez A, Mark Evers B. The role of NF-kappaB/IkappaB proteins in cancer: implications for novel treatment strategies. Surg Oncol. (1999) 8:143-53. doi: 10.1016/S0960-7404(00)00012-8

28. Jacobson-Brown P, Neuman MG. Colon polyps and cytokines: emerging immunological mechanisms. Rom J Gastroenterol. (2003) 12:207-14.

29. Csiszar A, Szentes T, Haraszti B, Balazs A, Petranyi GG, Pocsik E. The pattern of cytokine gene expression in human colorectal carcinoma. Pathol Oncol Res. (2004) 10:109-16. doi: 10.1007/BF02893465

30. Yuan A, Steigen SE, Goll R, Vonen B, Husbekk A, Cui G, et al. Dendritic cell infiltration pattern along the colorectal adenoma-carcinoma sequence. Apmis (2008) 116:445-56. doi: 10.1111/j.1600-0463.2008.00879.x

31. Yuan A, Chen JJ, Yao PL, Yang PC. The role of interleukin-8 in cancer cells and microenvironment interaction. Front Biosci. (2005) 10:853-65. doi: $10.2741 / 1579$

32. Contasta I, Berghella AM, Pellegrini P, Adorno D. Passage from normal mucosa to adenoma and colon cancer: alteration of normal sCD30 mechanisms regulating TH1/TH2 cell functions. Cancer Biother Radiopharm. (2003) 18:549-57. doi: 10.1089/108497803322287628

33. Pellegrini P, Berghella AM, Del Beato T, Cicia S, Adorno D, Casciani CU. Disregulation in $\mathrm{TH} 1$ and $\mathrm{TH} 2$ subsets of $\mathrm{CD}^{+} \mathrm{T}$ cells in peripheral blood of colorectal cancer patients and involvement in cancer establishment and progression. Cancer Immunol Immunother. (1996) 42:1-8. doi: $10.1007 / \mathrm{s} 002620050244$

34. Radosavljevic G, Ljujic B, Jovanovic I, Srzentic Z, Pavlovic S, Zdravkovic $\mathrm{N}$, et al. Interleukin-17 may be a valuable serum tumor marker in patients with colorectal carcinoma. Neoplasma (2010) 57:135-44. doi: 10.4149/neo_2010_02_135

35. Wang K, Kim MK, Di Caro G, Wong J, Shalapour S, Wan J, et al. Interleukin-17 receptor a signaling in transformed enterocytes promotes early colorectal tumorigenesis. Immunity (2014) 41:1052-63. doi: 10.1016/j.immuni.2014.11.009

36. Le Gouvello S, Bastuji-Garin S, Aloulou N, Mansour H, Chaumette MT, Berrehar F, et al. High prevalence of Foxp3 and IL17 in MMRproficient colorectal carcinomas. Gut (2008) 57:772-9. doi: 10.1136/gut.2007. 123794

37. Liu J, Duan Y, Cheng X, Chen X, Xie W, Long H, et al. IL-17 is associated with poor prognosis and promotes angiogenesis via stimulating VEGF production of cancer cells in colorectal carcinoma. Biochem Biophys Res Commun. (2011) 407:348-54. doi: 10.1016/j.bbrc.2011.03.021

38. De Simone V, Pallone F, Monteleone G, Stolfi C. Role of T17 cytokines in the control of colorectal cancer. Oncoimmunology (2013) 2:e26617. doi: 10.4161 /onci.26617

39. Chae WJ, Gibson TF, Zelterman D, Hao L, Henegariu O, Bothwell AL. Ablation of IL-17A abrogates progression of spontaneous intestinal tumorigenesis. Proc Natl Acad Sci USA. (2010) 107:5540-4. doi: $10.1073 /$ pnas.0912675107 
40. Wu S, Rhee KJ, Albesiano E, Rabizadeh S, Wu X, Yen HR, et al. A human colonic commensal promotes colon tumorigenesis via activation of T helper type $17 \mathrm{~T}$ cell responses. Nat Med. (2009) 15:1016-22. doi: 10.1038/n m.2015

41. Cui G, Shi Y, Cui J, Tang F, Florholmen J. Immune microenvironmental shift along human colorectal adenoma-carcinoma sequence: is it relevant to tumor development, biomarkers and biotherapeutic targets? Scand J Gastroenterol. (2012) 47:367-77. doi: 10.3109/00365521.2011.6 48950

42. Waldner MJ, Foersch S, Neurath MF. Interleukin-6-A key regulator of colorectal cancer development. Int J Biol Sci. (2012) 8:1248-53. doi: $10.7150 /$ ijbs.4614

43. Schmitz J, Owyang A, Oldham E, Song Y, Murphy E, McClanahan TK, et al. IL-33, an interleukin-1-like cytokine that signals via the IL-1 receptor-related protein ST2 and induces T helper type 2-associated cytokines. Immunity (2005) 23:479-90. doi: 10.1016/j.immuni.2005.09.015

44. Seidelin JB, Rogler G, Nielsen OH. A role for interleukin-33 in $\mathrm{T}(\mathrm{H}) 2$ polarized intestinal inflammation? Mucosal Immunol. (2011) 4:496-502. doi: $10.1038 / \mathrm{mi} .2011 .22$

45. Ramadan A, Land WG, Paczesny S. Editorial: danger signals triggering immune response and inflammation. Front Immunol. (2017) 8:979. doi: 10.3389/fimmu.2017.00979

46. De la Fuente M, MacDonald TT, Hermoso MA. The IL-33/ST2 axis: role in health and disease. Cytokine Growth Factor Rev. (2015) 26:615-23. doi: 10.1016/j.cytogfr.2015.07.017

47. Griesenauer B, Paczesny S. The ST2/IL-33 Axis in Immune Cells during Inflammatory Diseases. Front Immunol. (2017) 8:475. doi: 10.3389/fimmu.2017.00475

48. Jovanovic IP, Pejnovic NN, Radosavljevic GD, Pantic JM, Milovanovic $\mathrm{MZ}$, Arsenijevic NN, et al. Interleukin-33/ST2 axis promotes breast cancer growth and metastases by facilitating intratumoral accumulation of immunosuppressive and innate lymphoid cells. Int J Cancer (2014) 134:166982. doi: 10.1002/ijc.28481

49. Kim JY, Lim SC, Kim G, Yun HJ, Ahn SG, Choi HS. Interleukin-33/ST2 axis promotes epithelial cell transformation and breast tumorigenesis via upregulation of COT activity. Oncogene (2015) 34:4928-38. doi: $10.1038 /$ onc. 2014.418

50. Xiao P, Wan X, Cui B, Liu Y, Qiu C, Rong J, et al. Interleukin 33 in tumor microenvironment is crucial for the accumulation and function of myeloid-derived suppressor cells. Oncoimmunology (2016) 5:e1063772. doi: 10.1080/2162402X.2015.1063772

51. Schmieder A, Multhoff G, Radons J. Interleukin-33 acts as a proinflammatory cytokine and modulates its receptor gene expression in highly metastatic human pancreatic carcinoma cells. Cytokine (2012) 60:514-21. doi: 10.1016/j.cyto.2012.06.286

52. Chen SF, Nieh S, Jao SW, Wu MZ, Liu CL, Chang YC, et al. The paracrine effect of cancer-associated fibroblast-induced interleukin-33 regulates the invasiveness of head and neck squamous cell carcinoma. J Pathol. (2013) 231:180-9. doi: 10.1002/path.4226

53. Zhang P, Liu XK, Chu Z, Ye JC, Li KL, Zhuang WL, et al. Detection of interleukin-33 in serum and carcinoma tissue from patients with hepatocellular carcinoma and its clinical implications. J Int Med Res. (2012) 40:1654-61. doi: 10.1177/030006051204000504

54. Tong X, Barbour M, Hou K, Gao C, Cao S, Zheng J, et al. Interleukin33 predicts poor prognosis and promotes ovarian cancer cell growth and metastasis through regulating ERK and JNK signaling pathways. Mol Oncol. (2016) 10:113-25. doi: 10.1016/j.molonc.2015.06.004

55. Saied EM, El-Etreby NM. The role and prognostic value of inducible nitric oxide synthase (iNOS) and interleukin-33 (IL-33) in serous and mucinous epithelial ovarian tumours. Ann Diagn Pathol. (2017) 27:62-8. doi: 10.1016/j.anndiagpath.2017.01.006

56. Wang Z, Xu L, Chang Y, Zhou L, Fu H, Zhang W, et al. IL33 is associated with unfavorable postoperative survival of patients with clear-cell renal cell carcinoma. Tumour Biol. (2016) 37:11127-34. doi: 10.1007/s13277-016-4879-3

57. Hu LA, Fu Y, Zhang DN, Zhang J. Serum IL-33 as a diagnostic and prognostic marker in non-small cell lung cancer. Asian Pac J Cancer Prevent. (2013) 14:2563-6. doi: 10.7314/APJCP.2013.14.4.2563
58. Sun P, Ben Q, Tu S, Dong W, Qi X, Wu Y. Serum interleukin-33 levels in patients with gastric cancer. Digest Dis Sci. (2011) 56:3596-601. doi: 10.1007/s10620-011-1760-5

59. Maywald RL, Doerner SK, Pastorelli L, De Salvo C, Benton SM, Dawson EP, et al. IL-33 activates tumor stroma to promote intestinal polyposis. Proc Natl Acad Sci USA. (2015) 112:E2487-96. doi: 10.1073/pnas.1422445112

60. Zhang Y, Davis C, Shah S, Hughes D, Ryan JC, Altomare D, et al. IL33 promotes growth and liver metastasis of colorectal cancer in mice by remodeling the tumor microenvironment and inducing angiogenesis. $\mathrm{Mol}$ Carcinogen. (2017) 56:272-87. doi: 10.1002/mc.22491

61. Patel M, Horgan PG, McMillan DC, Edwards J. NF-kappaB pathways in the development and progression of colorectal cancer. Transl Res. (2018) 197:43-56. doi: 10.1016/j.trsl.2018.02.002

62. Pastorelli L, De Salvo C, Vecchi M, Pizarro TT. The role of IL-33 in gut mucosal inflammation. Mediators Inflamm. (2013) 2013:608187. doi: $10.1155 / 2013 / 608187$

63. Mertz KD, Mager LF, Wasmer MH, Thiesler $\mathrm{T}$, Koelzer VH, Ruzzante G, et al. The IL-33/ST2 pathway contributes to intestinal tumorigenesis in humans and mice. Oncoimmunology (2016) 5:e1062966. doi: 10.1080/2162402X.2015.1062966

64. Islam MS, Horiguchi K, Iino S, Kaji N, Mikawa S, Hori M, et al. Epidermal growth factor is a critical regulator of the cytokine IL-33 in intestinal epithelial cells. Br J Pharmacol. (2016) 173:2532-42. doi: 10.1111/bph.13535

65. Lu J, Kang J, Zhang C, Zhang X. The role of IL-33/ST2L signals in the immune cells. Immunol Lett. (2015) 164:11-7. doi: 10.1016/j.imlet.2015.01.008

66. O’Donnell C, Mahmoud A, Keane J, Murphy C, White D, Carey S, et al. An antitumorigenic role for the IL-33 receptor, ST2L, in colon cancer. Br J Cancer (2016) 114:37-43. doi: 10.1038/bjc.2015.433

67. Akimoto M, Maruyama R, Takamaru H, Ochiya T, Takenaga K. Soluble IL-33 receptor sST2 inhibits colorectal cancer malignant growth by modifying the tumour microenvironment. Nat Commun. (2016) 7:13589. doi: $10.1038 /$ ncomms13589

68. Choi YS, Choi HJ, Min JK, Pyun BJ, Maeng YS, Park H, et al. Interleukin33 induces angiogenesis and vascular permeability through ST2/TRAF6mediated endothelial nitric oxide production. Blood (2009) 114:3117-26. doi: 10.1182/blood-2009-02-203372

69. Qi H, Yang H, Xu G, Ren J, Hua W, Shi Y, et al. Therapeutic efficacy of IL-17A antibody injection in preventing the development of colitis associated carcinogenesis in mice. Immunobiology (2015) 220:54-9. doi: 10.1016/j.imbio.2014.09.002

70. Abdullah M, Rani AA, Sudoyo AW, Makmun D, Handjari DR, Hernowo BS. Expression of NF-kB and COX2 in colorectal cancer among native Indonesians: the role of inflammation in colorectal carcinogenesis. Acta Med Indonesiana (2013) 45:187-92.

71. Li Y, Shi J, Qi S, Zhang J, Peng D, Chen Z, et al. IL-33 facilitates proliferation of colorectal cancer dependent on COX2/PGE2. J Exp Clin Cancer Res. (2018) 37:196. doi: 10.1186/s13046-018-0839-7

72. Liang M, Liwen Z, Yun Z, Yanbo D, Jianping C. Serum levels of IL-33 and correlation with IL-4, IL-17A, and hypergammaglobulinemia in patients with autoimmune hepatitis. Mediators Inflamm. (2018) 2018:7964654. doi: 10.1155/2018/7964654

73. Pascual-Reguant A, Bayat Sarmadi J, Baumann C, Noster R, Cirera-Salinas D, Curato C, et al. TH17 cells express ST2 and are controlled by the alarmin IL-33 in the small intestine. Mucosal Immunol. (2017) 10:1431-42. doi: $10.1038 / \mathrm{mi} .2017 .5$

74. Liu X, Zhu L, Lu X, Bian H, Wu X, Yang W, et al. IL-33/ST2 pathway contributes to metastasis of human colorectal cancer. Biochem Biophys Res Commun. (2014) 453:486-92. doi: 10.1016/j.bbrc.2014.09.106

75. Kuchler AM, Pollheimer J, Balogh J, Sponheim J, Manley L, Sorensen DR, et al. Nuclear interleukin-33 is generally expressed in resting endothelium but rapidly lost upon angiogenic or proinflammatory activation. Am J Pathol. (2008) 173:1229-42. doi: 10.2353/ajpath.2008.080014

76. Stojkovic S, Kaun C, Heinz M, Krychtiuk KA, Rauscher S, Lemberger CE, et al. Interleukin-33 induces urokinase in human endothelial cells-Possible impact on angiogenesis. J Thromb Haemost. (2014) 12:948-57. doi: 10.1111/jth.12581

77. Tanabe T, Shimokawaji T, Kanoh S, Rubin BK. IL-33 stimulates CXCL8/IL-8 secretion in goblet cells but not normally differentiated airway cells. Clin Exp Allergy (2014) 44:540-52. doi: 10.1111/cea.12283 
78. Theoharides TC, Zhang B, Kempuraj D, Tagen M, Vasiadi M, Angelidou A, et al. IL-33 augments substance P-induced VEGF secretion from human mast cells and is increased in psoriatic skin. Proc Natl Acad Sci USA. (2010) 107:4448-53. doi: 10.1073/pnas.1000803107

79. Staton CA, Chetwood AS, Cameron IC, Cross SS, Brown NJ, Reed MW. The angiogenic switch occurs at the adenoma stage of the adenoma carcinoma sequence in colorectal cancer. Gut (2007) 56:1426-32. doi: 10.1136/gut.2007.125286

80. Hanrahan V, Currie MJ, Gunningham SP, Morrin HR, Scott PA, Robinson $\mathrm{BA}$, et al. The angiogenic switch for vascular endothelial growth factor (VEGF)-A, VEGF-B, VEGF-C, and VEGF-D in the adenoma-carcinoma sequence during colorectal cancer progression. J Pathol. (2003) 200:183-94. doi: 10.1002/path.1339

81. Clarke SL, Betts GJ, Plant A, Wright KL, El-Shanawany TM, Harrop R, et al. $\mathrm{CD}^{+}{ }^{+} \mathrm{CD} 25^{+} \mathrm{FOXP}^{+}$regulatory $\mathrm{T}$ cells suppress anti-tumor immune responses in patients with colorectal cancer. PLoS ONE (2006) 1:e129. doi: 10.1371/journal.pone.0000129

82. He Z, Chen L, Souto FO, Canasto-Chibuque C, Bongers G, Deshpande M, et al. Epithelial-derived IL-33 promotes intestinal tumorigenesis in $\mathrm{Apc}^{\mathrm{Min} /+}$ mice. Sci Rep. (2017) 7:5520. doi: 10.1038/s41598-017-05716-Z

83. Schiering C, Krausgruber T, Chomka A, Frohlich A, Adelmann K, Wohlfert EA, et al. The alarmin IL-33 promotes regulatory T-cell function in the intestine. Nature (2014) 513:564-8. doi: 10.1038/nature13577

84. Zhou Y, Ji Y, Wang H, Zhang H, Zhou H. IL-33 promotes the development of colorectal cancer through inducing tumor-infiltrating ST2 $\mathrm{L}^{+}$regulatory $\mathrm{T}$ cells in mice. Technol Cancer Res Treat. (2018) 17:1533033818780091. doi: $10.1177 / 1533033818780091$

85. Liu J, Shen JX, Hu JL, Huang WH, Zhang GJ. Significance of interleukin33 and its related cytokines in patients with breast cancers. Front Immunol. (2014) 5:141. doi: 10.3389/fimmu.2014.00141

86. Hu W, Wu C, Li X, Zheng Z, Xie Q, Deng X, et al. Serum IL-33 level is a predictor of progression-free survival after chemotherapy. Oncotarget (2017) 8:35116-23. doi: 10.18632/oncotarget.16627
87. Pohl M, Schmiegel W. Therapeutic strategies in diseases of the digestive tract--2015 and beyond targeted therapies in colon cancer today and tomorrow. Dig Dis. (2016) 34:574-9. doi: 10.1159/0004 45267

88. Sedhom MA, Pichery M, Murdoch JR, Foligne B, Ortega N, Normand S, et al. Neutralisation of the interleukin-33/ST2 pathway ameliorates experimental colitis through enhancement of mucosal healing in mice. Gut (2013) 62:171423. doi: 10.1136/gutjnl-2011-301785

89. Nguyen PM, Putoczki TL. Could the inhibition of IL-17 or IL-18 be a potential therapeutic opportunity for gastric cancer? Cytokine (2018). doi: 10.1016/j.cyto.2018.01.008. [Epub ahead of print].

90. Lucarini V, Ziccheddu G, Macchia I, La Sorsa V, Peschiaroli F, Buccione C, et al. IL-33 restricts tumor growth and inhibits pulmonary metastasis in melanoma-bearing mice through eosinophils. Oncoimmunology (2017) 6:e1317420. doi: 10.1080/2162402X.2017.1317420

91. Chen X, Lu K, Timko NJ, Weir DM, Zhu Z, Qin C, et al. IL-33 notably inhibits the growth of colon cancer cells. Oncol Lett. (2018) 16:769-74 doi: $10.3892 /$ ol.2018.8728

92. Jin Z, Liu H. IL-33 inhibits tumor growth through the activation of anti-tumor $\mathrm{CD}^{+} \mathrm{T}$ cell response in hepatocellular carcinoma. J Immunol. (2018) 200 (Suppl. 1):574.

Conflict of Interest Statement: The authors declare that the research was conducted in the absence of any commercial or financial relationships that could be construed as a potential conflict of interest.

Copyright (c) 2018 Cui, Yuan, Pang, Zheng, Li and Goll. This is an open-access article distributed under the terms of the Creative Commons Attribution License (CC $B Y)$. The use, distribution or reproduction in other forums is permitted, provided the original author(s) and the copyright owner(s) are credited and that the original publication in this journal is cited, in accordance with accepted academic practice. No use, distribution or reproduction is permitted which does not comply with these terms. 